\title{
Electric Power System Inertia: Requirements, Challenges and Solutions
}

\author{
Rezkalla, Michel Maher Naguib; Pertl, Michael Gerold; Marinelli, Mattia
}

Published in:

Electrical Engineering

Link to article, DOI:

$10.1007 /$ s00202-018-0739-z

Publication date:

2018

Document Version

Peer reviewed version

Link back to DTU Orbit

Citation (APA):

Rezkalla, M. M. N., Pertl, M. G., \& Marinelli, M. (2018). Electric Power System Inertia: Requirements, Challenges and Solutions. Electrical Engineering, 100(4), 2677-2693. https://doi.org/10.1007/s00202-018-0739-z

\section{General rights}

Copyright and moral rights for the publications made accessible in the public portal are retained by the authors and/or other copyright owners and it is a condition of accessing publications that users recognise and abide by the legal requirements associated with these rights.

- Users may download and print one copy of any publication from the public portal for the purpose of private study or research.

- You may not further distribute the material or use it for any profit-making activity or commercial gain

- You may freely distribute the URL identifying the publication in the public portal

If you believe that this document breaches copyright please contact us providing details, and we will remove access to the work immediately and investigate your claim. 


\title{
Electric Power System Inertia: Requirements, Challenges and Solutions
}

\author{
Michel Rezkalla* • Michael Pertl • Mattia Marinelli
}

Received: date / Accepted: date

\begin{abstract}
The displacement of conventional generation by converter connected resources reduces the available rotational inertia in the power system, which leads to faster frequency dynamics and consequently a less stable frequency behaviour. This study aims at presenting the current requirements and challenges that transmission system operators are facing due to the high integration of inertia-less resources. The manuscript presents a review of the various solutions and technologies that could potentially compensate for reduction in system inertia. The solutions are categorized into two groups, namely synchronous inertia and emulated inertia employing fast acting reserves (FARs). Meanwhile, FAR are divided into three groups based on the applied control approach, namely virtual synchronous machines, synthetic inertia control and fast frequency control. The analytical interdependency between the applied control approaches and the frequency gradient is also presented. It highlights the key parameters that can influence the units' response and limit their ability in participating in such services. The manuscript presents also a trade-off analysis among the most prominent control approaches and technologies guiding the reader through benefits and drawbacks of each solution.
\end{abstract}

This work is supported by the EU FP7 project ELECTRA (grant: 609687; electrairp.eu) and the Danish Research Project ELECTRA Top-up (grant: 3594756936313 ).

* corresponding author

M. Rezkalla, M. Pertl, M. Marinelli,

Technical University of Denmark

Department of Electrical Engineering

Frederiksborgvej 399

4000 Roskilde, Denmark

Tel.: +45 93511293 (Michel Rezkalla)

E-mail: $\{$ mirez,mpertl,matm\}@elektro.dtu.dk
Keywords Frequency Control, Synchronous inertia, Synthetic inertia · Virtual Synchronous Machine.

\section{Introduction}

Conventional power systems rely on electricity generation from large rotating synchronous generators (SGs). Due to the continuous exchange of energy between the rotating masses of the SGs and the grid, the dynamics of the grid frequency are limited and the frequency is maintained within an admissible range. Following a large disturbance, which causes the frequency to significantly deviate from its nominal value, the SGs releases the kinetic energy that is stored in their rotating masses as an inertia response. Additionally, SGs participate in primary and secondary frequency control by increasing/decreasing their active power generation [1].

Traditionally, inertia response has not been considered to be an ancillary service but has instead been considered as a natural characteristic of the power system. Due to the high integration of converter connected resources, which replace SGs, several transmission system operators (TSOs) in different countries have begun to recognize the value of the inertia response that can be provided by wind power plants, synchronous condensers, and emulated inertia $[2,3,4,5,6$.

To better comprehend the role of system inertia, Fig 1 shows how the system frequency could change after a contingency event in high and low inertia cases. The key parameters involved are: 1) Rate of change of frequency (RoCoF), 2) frequency nadir, and 3) steady state frequency.

Because the capacity of the primary frequency reserve (PFR) is the same in both inertia cases, the steady state frequency after the event settles at the same value. 


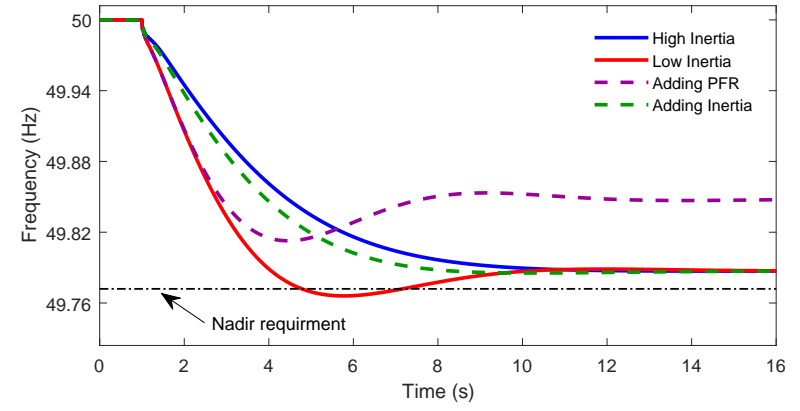

Fig. 1: Effects of lower inertia on system frequency performance

However, the lower inertia in the system exhibits a lower frequency nadir and a faster RoCoF. To maintain and operate the power system in a secure state, the three parameters that characterize the system frequency should be constrained to avoid further implications, such as load shedding, cascade tripping, and, in the worst case, system collapse.

The secure operation area for a given operating point can be represented by considering the previously mentioned frequency constraints. The authors in [7] represent the secure operation area by combining the PFR and inertia requirements, as shown in Fig 2. The secure area is delimited by the maximum allowed RoCoF (vertical line), the steady state frequency requirement (horizontal line), and the frequency nadir (red curve). The frequency nadir constraint is determined through the swing equation presented in 2) which depends on the PFR and the system inertia.

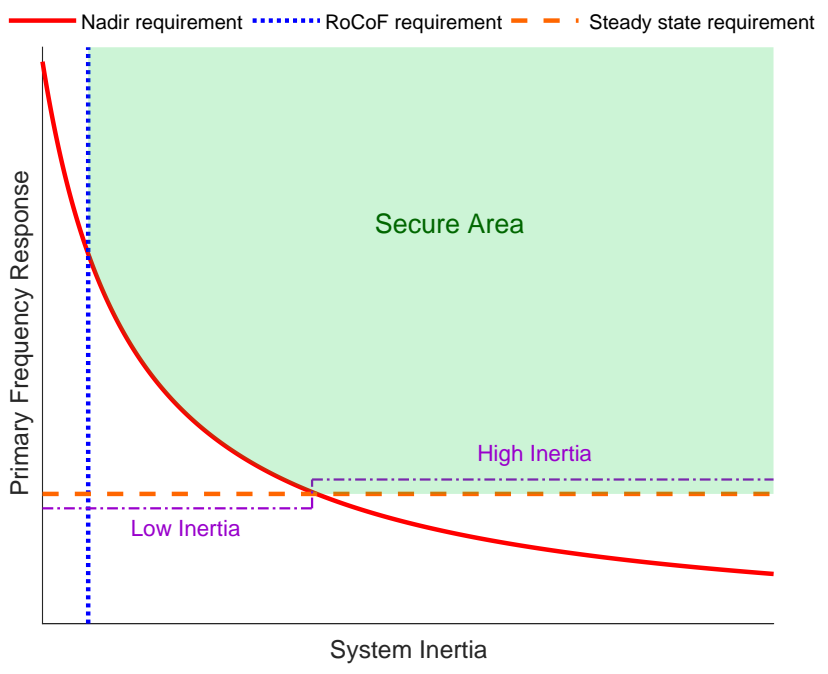

Fig. 2: Frequency response requirements adopted from 7 ]
Fig 2 shows that for high inertia cases, the PFR requirement is prevalent on the frequency nadir. In fact, due to the high inertia and the PFR reserve that is required to satisfy the steady state limit, the frequency nadir constraint will automatically be respected. This is also shown by the blue curve in Fig 1, where the steady state frequency is lower than the frequency nadir. In other words, due to the high inertia, the frequency declines at a slower rate allowing the activation of PFR before the nadir constraint is reached.

Nevertheless, moving towards low inertia system, the frequency nadir requirement starts to dominate on the steady state requirement. This requirement can be respected by acting on both $\mathrm{PFR}$ and/or system inertia, as shown by the dashed curves in Fig 1 . Indeed, the frequency nadir can be improved by adding PFR (purple dashed curve) and/or by augmenting system inertia (green dashed curve). The lower the system inertia, the faster the frequency will decline following an event (e.g. the loss of a generator). Hence, a faster primary reserve response is needed. In contrast, in high inertia grids, slower-acting primary reserves are adequate to cope with the imbalance. Fig 2 also shows that for low inertia cases, the RoCoF requirement starts to dominate on the frequency nadir. This is an indicator of how the grid requirements are evolving towards a new paradigm due to the high penetration of inertia-less resources.

TSOs with limited AC interconnection and high share of converter connected renewable energy sources (RES) have identified these issues to be of critical significance. For example, EirGrid, the Irish TSO has initiated the "Delivering a Secure Sustainable Electricity System (DS3)" program to address those challenges 8]. From TSO perspective, the reduction of system inertia has mainly two implications on system frequency stability, namely: 1) larger RoCoF, which results in possible tripping of grid components, especially embedded renewable generation; and 2) higher frequency deviations (nadirs/zeniths), potentially leading to load shedding and, in the worst case, system collapse. Moreover, conventional SGs are put to higher risk of instability as they are accelerating faster, thus reaching the maximal rotor angle earlier. Once the maximal rotor angle is exceeded pole slipping of the SG is very likely and protection will trip the generator putting even more strain on the system which eventually could lead to a cascade tripping [6].

This manuscript presents the analytical background of frequency variations and the capability of emulated inertia control (EIC) in mitigating the RoCoF and improving the frequency response. Challenges and solutions regarding the large-scale integration of converter-based units are discussed. In addition, the state-of-the-art of 
possible solutions and devices to improve the frequency response are discussed.

This study is part of the EU project ELECTRA 1 in which novel frequency and voltage control concepts to maintain and operate the power system in secure state are proposed. ELECTRA considers the grid inertia (i.e. synchronous and emulated inertia) as an active part of the frequency control process [9, 10.

This paper is structured as follows: Section 2 presents the grid requirements and some of the grid code modifications to maintain and operate the power system in secure state. It also presents the background for frequency variations and the inter-dependency between EIC and RoCoF. Section 3 presents the Various control approaches to mitigate the RoCoF and the advantages and drawbacks of each. The key parameters and challenges of each control approach are presented in Section 4. Section 5 presents the suitable technologies that can reduce the frequency gradient as well as the characteristics of each technology. Lastly, Section 6 presents the conclusion.

\section{Grid Requirements \& Synchronous Inertia}

\subsection{Grid Requirements}

The increasing share of distributed and inertia-less resources entails an upsurge in the requirements for balancing and system stabilization services. Various TSOs have identified these issues to be of critical significance and they have consequently initiated mitigating measures and established new requirements. In the following, an overview of some of the new requirements and grid code modifications is presented.

EirGrid, the Republic of Ireland's TSO, has proposed a RoCoF modification in the grid code to facilitate the delivery of the 2020 renewable targets while maintaining operational security on the power system. Generators are required to withstand a RoCoF event of $1 \mathrm{~Hz} / \mathrm{s}$ over $500 \mathrm{~ms}$ instead of $0.5 \mathrm{~Hz} / \mathrm{s}$ [11. Within the DS3 program and the RoCoF alternative studies, EirGrid and SONI (TSO of Northern Ireland) investigate the deployment of synchronous and non-synchronous inertia to maintain the RoCoF at $0.5 \mathrm{~Hz} / \mathrm{s}$ for a non-synchronous penetration of up to $75 \%$ [12. EirGrid and SONI have established a minimum value of rotational kinetic energy in the system as an operational constraint during the

1 The ELECTRA Integrated Research Program on Smart Grids brings together the partners of the EERA Joint Program on Smart Grids to reinforce and accelerate Europe's medium to long term research cooperation in this area and to drive a closer integration of the research programs of the participating organizations and of the related national programs. dispatch phase (i.e. $20 \mathrm{GWs)}$ and they refer to it as inertia floor [13]. It indicates the minimum amount of inertia that the system must have during all the operational hours. However, the total rotational energy of the system is defined as the sum of each machine's rated power multiplied with the relative inertia constant as in (1).

$E_{k i n}^{s y s}=\sum_{i=1}^{n} H_{i} S_{r, i}$

$H_{i}$ - inertia constant of the i-th generator (s)

$S_{r, i}$ - rated apparent power of the i-th generator (VA)

$E_{k i n}^{s y s}$ - total rotational kinetic energy of the system (Ws)

$n$ - number of generators

Due to the high share of inertia-less resources, UK's TSO, National Grid, started to procure fast reserves to provide the rapid delivery of active power through either increased output from a generator or the reduction of the demand to control frequency changes [14. This control mechanism is a frequency deviation based control and is addressed in this manuscript as fast frequency control (FFC).

The Hydro-Quebec Transenergie's (HQT) transmission connection requirement stipulates in detail that wind power plants must be equipped with an inertia emulation system. HQT is now in the process of procuring and validating manufacturers' models integrating inertia emulation features [15,16. This control mechanism is a RoCoF based control and addressed further as synthetic inertia control (SIC).

This manuscript will demonstrate analytically the ability of FFC and SIC in limiting the frequency gradient and improving the frequency response. Advantages and drawbacks of each controller are also discussed.

\subsection{Synchronous Inertia}

Inertia is defined as the resistance of a physical object to a change in its state of motion including changes in speed and direction [17. With reference to the power systems, the inertia refers to the rotating machines directly connected to the electrical grid without any power converter (e.g. SGs, induction generators and motors, etc.). The resistance to change in rotational speed is expressed by the moment of inertia of the rotating mass. Traditionally, the total inertia of a power system is determined by the large rotating masses of conventional power plants, i.e. the generator and turbine connected to the same shaft. Due to the synchronous coupling of the machines with the grid, their rotational speed (i.e. $\omega_{m}$ ) is linked with the angular velocity of 
the electromagnetic field (i.e. $\omega_{e}$ ). During a disturbance which causes an imbalance between the two opposing torques, the net torque on the rotor is different from zero leading to an acceleration or deceleration according to the electro-mechanical swing equation in (2).

$J \frac{d \omega_{m}}{d t}=T_{m}-T_{e}=T_{a}$

$J$ - combined moment of inertia of the generator and the turbine $\left(\mathrm{kg} \cdot \mathrm{m}^{2}\right)$

$T_{m}$ - mechanical torque $(\mathrm{N} \cdot \mathrm{m})$

$T_{e}$ - electrical torque $(\mathrm{N} \cdot \mathrm{m})$

$T_{a}$ - acceleration/deceleration torque $(\mathrm{N} \cdot \mathrm{m})$

SGs are characterized by their inertia constant $H$ which is defined as the kinetic energy $E_{k i n}$, stored in the rotating mass at rated speed, divided by the machine rating power $S_{r}$ as shown in (3).

$H=\frac{E_{k i n}}{S_{r}}=\frac{J \omega_{m, 0}^{2}}{2 S_{r}}$

$\omega_{m, 0}$ - rated mechanical angular velocity $(\mathrm{rad} / \mathrm{s})$

$\omega_{e}=p \omega_{m}$, where $\mathrm{p}$ is the number of pole pairs. Assuming $\mathrm{p}=1$, equation (2) and (3) can be reformulated as:

$P_{m}-P_{e}=\omega_{m} \frac{2 H S_{r}}{\omega_{m, 0}^{2}} \frac{\mathrm{d} \omega_{m}}{\mathrm{~d} t}$

$P_{m}$ - mechanical power $(\mathrm{W})$

$P_{e}$ - electrical power $(\mathrm{W})$

$\omega_{e}$ - angular velocity of the electromagnetic field ( $\left.\mathrm{rad} / \mathrm{s}\right)$

For limited angular velocity variation, one can assume $\omega_{m}=\omega_{m, 0}$, thus (4) can be reformulated as:

$P_{m}-P_{e}=\frac{2 H S_{r}}{\omega_{m, 0}} \frac{\mathrm{d} \omega_{m}}{\mathrm{~d} t}$

Assuming that $P_{m}$ is constant and that the frequency regulation is only from the load side, then one can consider that $P_{e}$ is composed by: frequency dependent loads $\left(P_{D}\right)$, devices participating in FFC $\left(P_{F F C}\right)$ and devices participating in $\mathrm{SIC}\left(P_{S I C}\right)$ :

$P_{e}=P_{D}+P_{F F C}+P_{S I C}$

Where each is composed by a base value and frequency dependent value:

$$
\begin{aligned}
& P_{D}=P_{D_{0}}+K_{D}\left(\omega_{e}-\omega_{m, 0}\right) \\
& P_{F F C}=P_{F F C_{0}}+K_{F F C}\left(\omega_{e}-\omega_{m, 0}\right) \\
& P_{S I C}=P_{S I C_{0}}+K_{S I C} \frac{\mathrm{d} \omega_{e}}{\mathrm{~d} t}
\end{aligned}
$$

$P_{D_{0}}, P_{F F C_{0}}$ and $P_{S I C_{0}}$ represent the base electric power in steady state and addressed further as $P_{e_{0}}=P_{D_{0}}+$ $P_{F F C_{0}}+P_{S I C_{0}} \cdot K_{D}$ is a damping factor, it considers the electrical loads that change their active power consumption due to frequency changes. $K_{F C C}=K_{F C C}(t-t 0)$ is the FCC proportional control coefficient. $K_{S I C}=$ $K_{S I C}(t-t 0)$ is the SIC proportional control coefficient. $K_{F C C}$ and $K_{S I C}$ are represented in function of the time to represent the time required by the devices to be activated: $t 0$ represents the delay. $K_{F C C}$ and $K_{S I C}$ are represented in function of the time to represent the time required from those devices to get activated (i.e. time delay), $t$ represent the time while $t 0$ represent the delay.. Therefore the electric power $P_{e}$ can be expressed as:

$P_{e}=P_{e_{0}}+\left(K_{D}+K_{F F C}\right)\left(\omega_{e}-\omega_{m, 0}\right)+K_{S I C} \frac{\mathrm{d} \omega_{e}}{\mathrm{~d} t}+\Delta P_{e}$

Where $\Delta P_{e}$ is the perturbation and in steady state the $P_{m}$ is equal to $P_{e_{0}}$. The swing equation can be formulated as:

$$
\frac{2 H \frac{\mathrm{d} \omega_{e}}{\mathrm{~d} t}}{\omega_{m, 0}}=-\left(K_{D}+K_{F F C}\right)\left(\omega_{e}-\omega_{m, 0}\right)-K_{S I C} \frac{\mathrm{d} \omega_{e}}{\mathrm{~d} t}-\Delta P_{e}
$$

Assuming that $K_{F F C}$ and $K_{S I C}$ are deployed by unit characterized by a very small time constant $(t 0)$, it is possible to decouple units' dynamics with frequency variations. The frequency can be therefore considered as quasi-constant value while the unit provide either $K_{F F C}$ or $K_{S I C}$ considering that the variation in power output will be much faster of the frequency dynamics. Therefore, the differential equation can be solved as:

$\omega(t)=\omega_{m, 0}+\left(\frac{e^{-\frac{\left(K_{D}+K_{F F C}\right) \omega_{m, 0}}{K_{S I C} \omega_{m, 0}+2 H S_{r}} t}}{K_{D}+K_{F F C}}-\frac{1}{K_{D}+K_{F F C}}\right) \Delta P_{e}$

$\frac{\mathrm{d} \omega(t)}{\mathrm{d} t}=-\omega_{m, 0} \frac{e^{-\frac{\left(K_{D}+K_{F F C}\right) \omega_{m, 0}}{K_{S I C} \omega_{m, 0}+2 H S_{r}} t} \Delta P_{e}}{k_{S I C} \omega_{m, 0}+2 H S_{r}}$

One can notice that both FFC and SIC affect the RoCoF variation during the transient. One can notice that due to the response time of FFC and SIC and the power ramp-rate limitations of the used resource (e.g. battery ramp-rate), it turns out to be a complex time-variant term. Nevertheless, the presented swing equation shows clearly that mitigating the impact of power imbalances in terms of RoCoF can be achieved by increasing the system rotational inertia $\mathrm{H}$, employing fast reserves with RoCoF based control and/or with frequency deviation based control. 


\section{Various Solutions to for EIC}

As analytically shown in 13 , the system RoCoF can be mitigated by one of the following actions: increasing the system rotational inertia $\mathrm{H}$ and/or employing fast reserves with EIC approaches. EIC can be distinguished in three categories, namely virtual synchronous machines (VSM), SIC and FFC. Fig 3 presents an overview of the different solutions. In the following, a qualitative analysis of EIC approaches is presented.

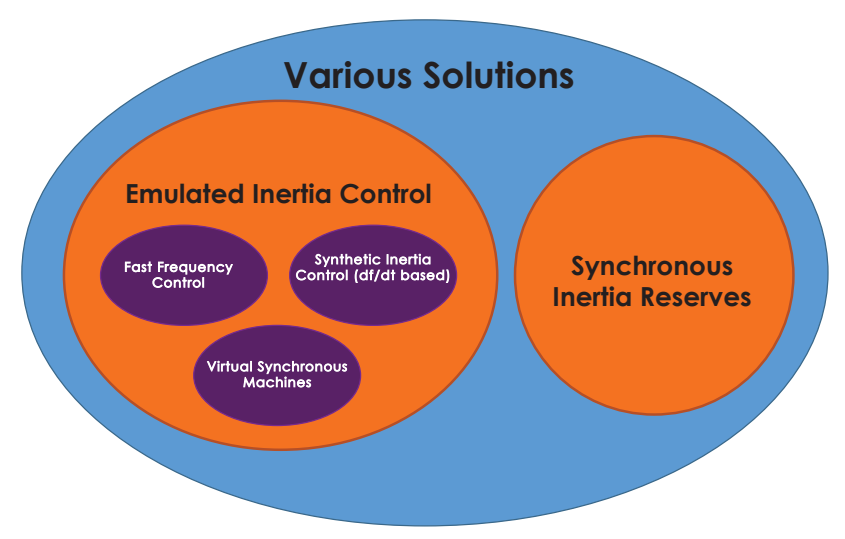

Fig. 3: Various Solutions

For machines/units which are connected to the grid by means of power electronics, the electromagnetic coupling between grid and prime mover does not exist, e.g. Type 4 wind turbines 18 . Therefore, frequency changes will not induce a natural power change from the device and, in principle, they can only provide emulated inertia response.

Devices which are connected to the grid through power electronics could provide emulated inertia if the active power absorbed or generated is achieved through control strategy based on the frequency variation over time $\left(\frac{\Delta f}{\Delta t}\right)$, emulating the synchronous inertia behaviour. Emulated inertia could also be achieved by extracting the kinetic energy stored in the rotating parts through dedicated control scheme as the case with wind turbines Type 3 and Type 4 [19,20].

Emulated inertia is a combination of control algorithms, renewable energy resources, energy storage systems and power electronics that emulate the inertia of a conventional power system [21]. The general concept of EIC is presented in Fig 4 . The core of the system is the emulated inertia algorithm which varies among the different solutions, based on the application and the desired level of model sophistication 22. Some typologies try to mimic the exact behaviour of the SG through a detailed mathematical model that represents the SG's dynamics, which are generally addressed as VSM. Meanwhile, other approaches have tried to simplify this by using just the swing equation, which is further indicated as SIC.

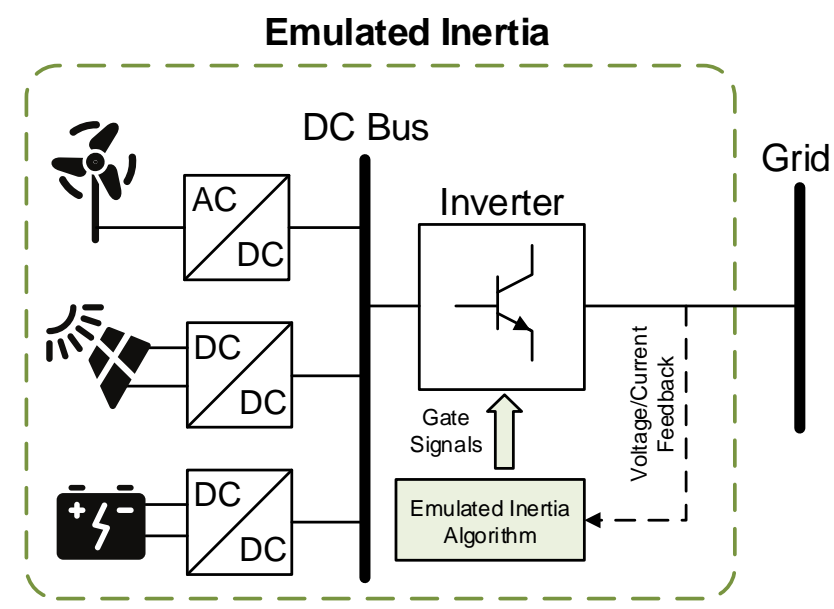

Fig. 4: Emulated inertia concept

\subsection{Virtual Synchronous Machines}

The first proposal of a VSM was published by Beck and Hesse in 2007, who labeled as VISMA 23. The underlying idea behind the VSM concept is to emulate the essential behaviour of a real SG by controlling a power electronic converter. Thus, any VSM implementation contains more or less explicitly a mathematical model of a SG 24. The inertia emulation is a common feature for every VSM control scheme and it is based on the desired degree of accuracy in reproducing the SG dynamics, while additional aspects can be included or neglected (e.g transient and sub-transient dynamics).

If the purpose of VSM is to accurately replicate the dynamic behaviour of a SG, then a full order model of the SG has to be included in the converter control system. This includes a $5^{\text {th }}$ order electrical model with dq-representation of stator windings, damper windings and the field winding, together with a $2^{\text {nd }}$ order mechanical model resulting in a $7^{t h}$ order model 25, 26. An example of a VSM type is presented in Fig 5. This type is used by the European VSYNC research group [27, 28] and has demonstrated the effectiveness of inertia emulation through real-time simulations [29] and field test [30].

Various control schemes for VSM, which represents the interface between the SG models and the power electronic converter, have been presented and discussed in the literature $22,24,25,26,23$. The control schemes 


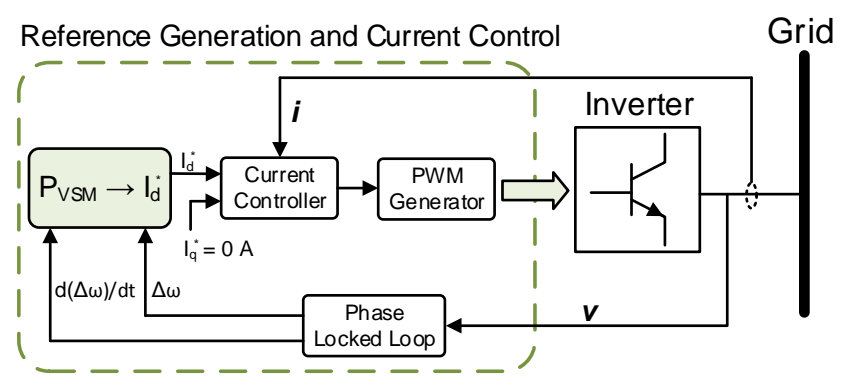

Fig. 5: Virtual Synchronous Machine Type

proposed in literature can be categorized into two main groups based on the nature of the output reference from the SG model, namely: Voltage Reference and Current Reference models.

1. Voltage Reference: This control scheme is configured to provide a voltage reference output 31. If a reduced order model of the SG is applied, then the power flow will be mainly related to the inertia emulation and the phase angle resulting from the swing equation. However, protections can be implemented at the hardware level or as parallel loops, over-riding the references from the VSM; however, their interaction with the inertia emulation and the resulting behaviour can be difficult to predict [24].

2. Current Reference: This control approach generates a current reference. This scheme allows the implementation of high order electrical models for the SG [23]. Nevertheless, in practical implementations, this scheme can lead to numerical instability, especially with high order SG models 32].

\subsection{Synthetic Inertia Control}

The inertia response can be also emulated by tracking the RoCoF and representing the SG only by the swing equation, as shown in (9). The control structure is shown in Fig 6 - a and is only emulating the inertia effect with respect to the response to changes in the frequency gradient. A key parameter in this controller is the RoCoF measurement, which is further addressed in Section 4.1. However, this control system does not have the inherent capability for black-start since it requires the system frequency as an input.

\subsection{Fast Frequency Control}

FFC is a frequency deviation based control and is achieved by a joint action of FFC providing units within the synchronous area. FFC employs the same control mechanism as PFR which is generally achieved using droop
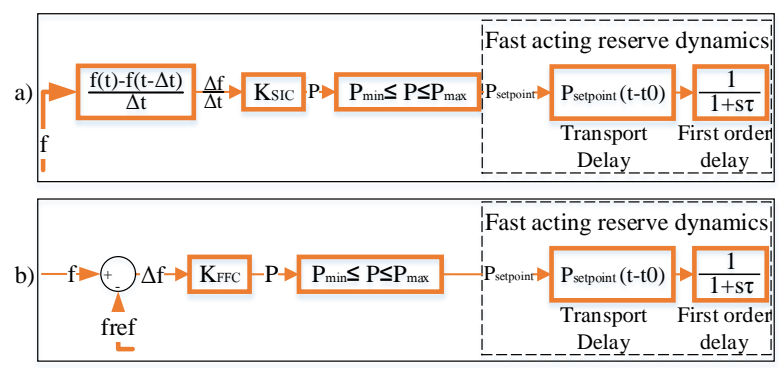

Fig. 6: SIC and FFC control diagram

controllers, so that governors operating in parallel can share the load variation according to their rated power. The droop constant represents the ratio of frequency deviation to change in power output 33 . The frequency variation, $\Delta f(\mathrm{~Hz})$, which is referred to the nominal frequency of the system, is therefore given as a function of the relative power change $\Delta P(\mathrm{~W})$ reported to the nominal machine power, as shown in (14) and in Fig 7 However, governors' dynamics (e.g. response time and ramping rate) limit the PFR capability in improving the RoCoF. On the other hand, FFC is characterized by employing FAR, for example, energy storage and electric vehicles 34. The FFC control diagram is presented in Fig 6-b.

$\frac{-1}{K_{F F C}}=\frac{\Delta f / f_{\text {nom }}}{\Delta P / P_{\text {nom }}}$

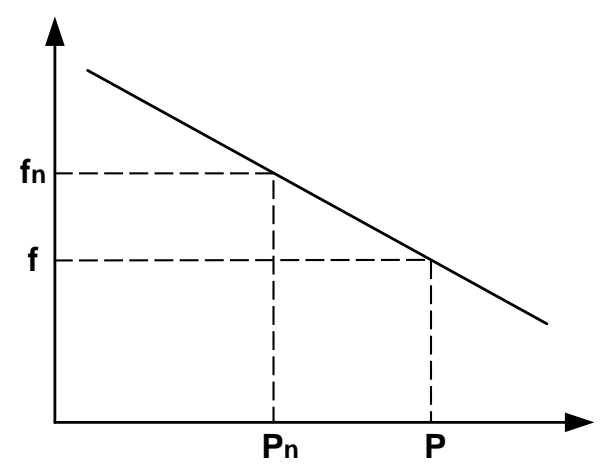

Fig. 7: Frequency control droop characteristic

A summary which highlights the key features and weaknesses of the various inertia control schemes is presented in Table 1 .

\section{Key Parameters \& Challenges}

Emulated inertia services are mainly characterized by the controller and the device dynamics. Different param- 
ht]

Table 1: Overview of the Various Control Schemes

\begin{tabular}{|c|c|c|}
\hline Control Schemes & Key Features & Weaknesses \\
\hline VSM & $\begin{array}{l}\text { - Accurate representation of SG model } \\
\text { - Frequency derivative not required } \\
\text { - Black-start capability }\end{array}$ & $\begin{array}{l}\text { - Can lead to numerical instability } \\
\text { Protections of the voltages and currents } \\
\text { of the converter cannot be easily in- } \\
\text { cluded }\end{array}$ \\
\hline $\mathrm{SIC}$ & $\begin{array}{l}\text { - Simple implementation compared to } \\
\text { VSM }\end{array}$ & $\begin{array}{l}\text { - Frequency derivative required } \\
\text { - No black-start capability } \\
\text { - System susceptible to noise }\end{array}$ \\
\hline FFC & $\begin{array}{l}\text { - Control type similar to conventional } \\
\text { droop control in SGs } \\
\text { - Local control (i.e. communication-less) } \\
\text { - Stable performance }\end{array}$ & - No black-start capability \\
\hline
\end{tabular}

eters can radically change the controller and the device response and, therefore, their ability in delivering such services. The key parameters can be divided into four groups: 1) Signal measurement parameters, 2) Response time, 3) Dead-band and 4) Device performance. Moreover, there is a lack of clarity regarding the volume of FAR that can potentially compensate for reduction in system inertia and the effects of the previously mentioned parameters on the required volume of FAR. In other words, the quantitative relationship between MW of reserve and the corresponding MWs of synchronous inertia that those will be able to replace. In the following an overview of the different key parameters are presented.

\subsection{Signal Measurement and Processing}

Conventionally, utilities have used the speed of SGs as a proxy for the grid frequency because it is relatively easy and accurate to measure. Generators' governors have been using deviations in rotor speed as measure for frequency deviation from the reference ever since. In contrast, converter connected resources delivering frequency support as well as protection relays (e.g. under-frequency and RoCoF relays) need to measure the frequency directly from the grid. In the following, an overview of the most common methods to measure the system frequency and the RoCoF, and the associated key challenges are presented:

\section{- Frequency Measurement:}

The system frequency indicates the dynamic balance between power generation and consumption, and it is measured from voltage or current signals, which originate from the synchronous machines whose rotating speed are proportional to the frequency of the generated voltage. The system frequency and its rate of change are used directly in various protections and control schemes and low measurement accuracy (e.g. due to harmonics, random noise electromagnetic interference, etc.) can cause false operation leading to system instability.

The zero crossing algorithm which uses a pulse counting between zero crossings of the signal was the mostly commonly adopted method 35. Nowadays, with the technological progress in microprocessors and cheaper computational power, many numerical method for frequency measurement are applied and proposed:

- Modified Zero-crossing method [36, 37, 38.

- Digital Fourier Transformation [39,40,41]

- Phase locked loop 42,43,44

- Orthogonal decomposition 45,46]

- Least square optimization 47,48]

- Taylor approximation 49,50

- Numerical analysis [51,52]

- Artificial intelligence [53,54,55.

To evaluate the performance of a frequency estimation method, the following three aspects should be considered: the accuracy, the estimation of latency and the robustness. The maximum error, the average error and the estimation delay could be used as the performance indexes for frequency measurements. The maximum error is the difference between the actual frequency and the estimated frequency. The average error is based on a number of data points in which the average values are taken for both, the actual and estimated frequency [35]. Most frequency estimation algorithms employs a window of data to derive the frequency, which causes estimation delay because the frequency is time-varying. On the one hand, a small window of data will reduce the estimation delay while, on the other hand, it reduces the 
measurement accuracy due to the presence of noise and harmonics. One can see that frequency measurement is quite a challenging task and measurement errors or latency can lead to malfunction of protection or control schemes.

\section{- RoCoF Measurement:}

A key parameter in delivering synthetic inertia is the RoCoF measurement. The RoCoF is the time derivative of the power system frequency $(d f / d t)$ which varies in function of the chosen measurement window. This quantity was traditionally of minor relevance for systems with generation mainly based on SGs, because of the inertia of these generators, which inherently counteract to power imbalances and thus limiting the RoCoF.

A key issue in the measurement of RoCoF across the system is that the frequency measured at different points in the system can vary significantly under transient conditions. During transient events generator rotor speeds may also differ from each other due to local and inter-area interactions [56]. To obtain a consistent system wide measurement of RoCoF, the electrical transients need to be removed from the analysis and only the mechanical transients on the system should be considered [13. By extending the measurement window, the electrical transients can be removed from the RoCoF measurement, allowing for a more consistent system RoCoF to be determined [57]. Meanwhile, relatively large measurement windows might also eliminate the mechanical transients leading to false RoCoF values. Fig 8 illustrate the effect of using different measuring windows on the RoCoF value. For example, considering a certain system with certain dynamics and employing a measuring window of $100 \mathrm{~ms}$, the calculated RoCoF is $2.1 \mathrm{~Hz} / \mathrm{s}$ versus $0.9 \mathrm{~Hz} / \mathrm{s}$ for a $500 \mathrm{~ms}$ measuring window. Therefore, the chosen measuring window, over which the RoCoF is calculated, is just as important as the RoCoF value itself.

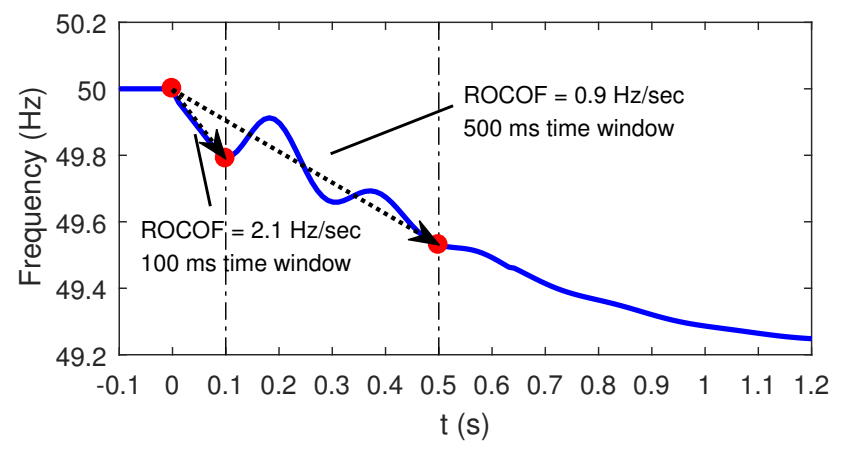

Fig. 8: Illustration of frequency change and the effect of using different measuring windows
This issue is also of concern for various TSOs because the distributed energy resourcess (DERs) employ protection schemes for loss-of-mains. Generally these schemes utilize under- and over-frequency relays as well as RoCoF relays. These schemes aim to ensure that, should a part of the distribution network become islanded from the rest of the distribution system, that there is no generation left operating on that local system, keeping it live [58. From the TSO perspective, "false" RoCoF values that are influenced by the electrical transients might lead to unintended cascade tripping of distributed energy resources connected by means of RoCoF relays [59,60]. Moreover, different studies have shown that commercially available RoCoF relays from different manufacturers respond differently to the same event, even when they are configured with the same settings 61,62,63. This phenomenon is most likely due to the different measurements techniques employed by those relays. On the other hand, from the rotary electrical machine perspective, the use of a relatively large measurement window might lead to neglecting the mechanical transient and thus increasing the mechanical stress on the rotating machines $[64,65]$.

Generally, the grid code establishes the required RoCoF relays' characteristics (e.g. measurement window and threshold), which varies among countries. For example, the Irish grid code defines $1 \mathrm{~Hz} / \mathrm{s}$ the RoCoF relays' threshold measured over $500 \mathrm{~ms}$ moving window. EirGrid determined that $1 \mathrm{~Hz} / \mathrm{s}$ would be sufficient to cover for the loss of the current largest single infeed (i.e. East-West interconnector exporting $500 \mathrm{MW}$ ) 58. This choice is to guarantee the triggering of the reserves only for events which can threat the system stability by triggering RoCoF relays.

\subsection{FAR Device Response Time}

The response time is defined as the total time required from the FAR device to actively supply the grid with its service. For power electronic connected technologies, delivering synthetic inertia and/or fast frequency control, there is a delay between the event the device's response 66. The response time can be represented by a combination of the following four different parameters:

- Measurement time, which is the time needed to detect and measure the RoCoF (or frequency in case of FFC)

- Signal time, which is the time required to get the activation signal from the measurement device to the FAR device. 
- Activation time, which is the time required from the FAR device to deliver the initial power response once it received the activation signal.

- Ramping time, which is the time required from the FAR to ramp up to the required active power setpoint.

However, an adequate response time depends on the system dynamics and requirements such as system inertia and RoCoF limits. For example, a unit with a certain response time adequate for high inertia systems might lead to frequency oscillation in a low inertia system.

Generally, for low inertia system, the response time is of more importance than for high inertia systems. The authors in 67] present a sensitivity analysis of the response time and highlight its importance and impacts on the system stability.

\subsection{Deadband}

Deadbands are generally categorized into unintentional and intentional deadbands.

Unintentional deadband terminology is used to describe the inherent effect of a unit; for example, to describe the mechanical effect of a turbine-governor system, such as sticky valves, loose gears, and hydraulic system non-linearity, which are unavoidable and unadjustable 68].

In contrast, an intentional deadband is commonly applied for control purposes. For example, in the case of primary frequency control (PFC), an intentional deadband is applied to the governor control systems to reduce excessive controller activities for acceptable frequency fluctuations. For the governor control system, deadband values are established by the grid code 69. For example, Republic of Ireland's grid code requires that a frequency deadband of no greater than $\pm 15 \mathrm{mHz}$ maybe applied to the operation of the governor control system [58]. In the Continental Europe a frequency deadband of $\pm 20 \mathrm{mHz}$ is permitted. On the other hand, some grid codes such as in the Nordic area, require that primary frequency support must be made without deadband [70]. However, one should differentiate between contingency based and regulation based service. When employing FAR for regulation based services, the controller should employ the same deadband established by the grid code for the governors control system. In the case of contingency based services, defining a deadband is a more complicated task, In fact it depends on the system characteristics such as the system inertia.

\subsection{Device performance}

As previously mentioned, the FAR response is highly influenced by the controller as well as the device dynamics. In the following the key parameters that can influence the FAR response are presented:

- Response time: The time required by the device to react to frequency fluctuation.

- Active power ramp: The rate at which the active power will ramp after a frequency changes.

- Active power amplitude: The amount of active power delivered from the device in function of frequency changes.

- Active power duration: The time period for which the device will provide active power before its energy has been depleted. In case of employing FAR for synthetic inertia, this parameter has a lower importance compared to FFC since SIC focuses on very small time frame post event.

\subsection{Quantitative relationship between MW and MWs}

The high integration of converter connected resources is resulting in the reduction of the system inertia and consequently deterioration of frequency stability. FAR units controlled through SIC or/and FFC is seen as a possible solution and various control approaches have been previously proposed in different studies. Nevertheless, there is a lack of clarity regarding the volume of FAR in terms of MW that can potentially compensate for the reduction of a certain MWs of synchronous inertia.

\section{Suitable Technologies for mitigating the RoCoF}

This section provides a high level assessment of the different technologies that may be used to mitigate the RoCoF. Two groups can be distinguished: 1) synchronous inertia, and 2) emulated inertia employing FARs. On the one hand, synchronous inertia reserves are characterized by their inherent inertia response, which does not require any measurement or control schemes. On the other hand, FARs enhanced by FFC controllers are able to mitigate the $\mathrm{RoCoF}$ and frequency nadir.

The assessment is based on the following criteria: 1) Geographic limitation, 2) Additional system services (e.g. voltage control and black start), 3) Type of the provided inertia service, 4) Inertia constant $\mathrm{H}(\mathrm{s})$ and the typical power capacity (MW), and 5) Capital cost.

\section{AC Interconnection}


An $\mathrm{AC}$ interconnection between two power systems, by means of overhead lines or cables, will lead to a single synchronous network. In case of loss of generation, the inertia of both power systems will start to supply the power imbalance, leading to lower RoCoF and better frequency performance [71,13.

- Geographic limitation

Geographical flexibility and large distance play a significant role regarding $\mathrm{AC}$ interconnectors installation. For example, if an interconnector was to be built between the Island of Ireland and United Kingdom, the distance would be one of the world's longest sub-marine AC cables, which is likely to challenge current technology.

- Additional system services

The power system will be strengthened due to the connection of the two subsystems. To be noted, in case of AC interconnection through long high voltage cables, the charging current limits the power transfer capability 72 .

- Type of the inertia response

Inherent inertia response improving the overall frequency performance.

- Inertia constant and power capacity range For AC inerterconnectors, the inertia constant depends on the inertia of the two interconnected systems. The power capacity depends on the interconnecting link.

- Capital cost

$\mathrm{AC}$ interconnection depends on the distance of the two connected systems as well as the geography and on the geography, which determines the possibility of using overhead lines or cables.

\section{Compressed Air Energy Storage}

Energy storage systems are effective for supporting the integration of renewable energy and delivering system services. Compressed air energy storage (CAES) is a promising energy storage technology due to its high efficiency, cleanness and long service life [3]. CAES makes use of underground caverns where air is compressed for storage and decompressed in order to release the stored energy. A CAES plant consists of a large volume that can store the compressed air (the battery) and, what is in principle, a gas turbine. The plant store the compressed air underground in caverns or rock formations [74].

- Geographic limitation

One can notice that the geology plays a significant role for this technology since it requires an underground cavern limiting its applicability.
- Additional system services CAES is capable of providing multiple system services as frequency and voltage support.

- Type of the inertia response CAES is characterized by its synchronous inertia response.

- Inertia constant and power capacity range Inertia constant in the range of $H=\{3-9\} \mathrm{s}$ and power capacity that range between $\{15-$ 600\} MW 64,75, 13 .

- Capital cost

Based on the analysis on $2^{\text {nd }}$ generation CAES, estimated capital costs range between $\{750-$ $1000\}$ EUR/kW 76.

3. Power Plant Technical Minimum Reduction One possible solution for maintaining the same inertia level while allowing greater headroom for nonsynchronous generation is by operating SGs at low power setpoints. Most conventional power plants are designed to run in the upper capacity range closer to the rated power with a minimum low power setpoint. Reducing the minimum setpoint value is another option with the same benefits. However, the power plant type plays a fundamental role for the provision of this service. For example, thermal power plants operating in the lower output range are characterized by high $\mathrm{CO}_{2}$ emissions [77.

- Geographic limitation

There are no location restrictions because it uses existing power plants.

- Additional system services

The same system services of a conventional plant operating in normal conditions but reduced down-regulation reserves.

- Type of the inertia response Synchronous inertia response.

- Inertia constant and power capacity range The inertia time constant is not alterated and it is the same as for conventional plants which is in the range of $H=\{2-9\} \mathrm{s}$ and power capacity of $\{0.1-1\}$ GW $[13,78,64,75]$.

- Capital cost

This depends on the type of plant and if a refurbishment is needed.

\section{Pumped Storage Hydro}

Although utility-sized energy storage systems are a small percentage of the total generating capability of the power system, they are increasingly gaining attention for their role in enabling higher penetrations of variable renewable resources into the grid [79]. Currently, pumped hydroelectric storage (PHS) is the most common type of utility-scale storage [80]. 
The authors of a 2012 white paper by the National Hydro-power Association's Pumped Storage Development Council indicated that development of new PHS, particularly in areas with increased wind and solar capacity, would significantly improve system reliability while reducing the need to construct new fossil-fuel generation 81. Simultaneously, the power range of pumped storage devices are suitable for delivering sufficient synchronous inertia, although significantly lower than that of a gas or coal fired power plant 80. However, this technology requires the construction of an upper and a lower basin, which delimits its application in some countries due to geographical limitations.

\section{- Geographic limitation}

The geographical circumstance is a key requirement to be able to employ this technology. It requires the construction of an upper and a lower basin, which delimits its application to areas which fulfill these requirements.

- Additional system services

PHS is able to provide various system services as conventional power plants. . Additionally, pumped hydro power plants can also consume active power from the grid to pump water from the lower basin to the higher basin.

- Type of the inertia response

Synchronous inertia response due to direct grid connection.

- Inertia constant and power capacity range Inertia constant in the range of $H=\{2-4\} \mathrm{s}$ and power capacity of $\{1-3000\}$ MW [78,82].

- Capital cost

Capital costs for PHS differ widely. Reliable, experimentally confirmed numbers are only available for traditional geographically determined installations and reported to be in the range of $\{800-1000\} \mathrm{EUR} / \mathrm{kW} 76$.

\section{Synchronous Condensers}

synchronous condenserss (SCs) are machines that are synchronized with the power system and operate as free spinning motors. SCs have played an important role in reactive power compensation and they have contributed to voltage stability in power systems for more than 50 years 83,84 . Currently, several TSOs have started to investigate SCs effect in mitigating the RoCoF and enhancing the frequency stability 85. Nevertheless, SCs are characterized by a lower inertia compared to conventional plants because the prime mover's mass is missing. However, in some cases, SCs can be equipped with additional masses to increase the inertia.
- Geographic limitation

SCs are not influenced by the geographic location and, in principle, are flexible to install. Moreover, existing power plants can be converted to synchronous condensers.

- Additional system services

As previously mentioned, SCs have been used for many years for reactive power compensation to improve voltage stability.

- Type of the inertia response

Due to grid connection without power converters, they are able to provide an inherent inertia response without the need for measurements and controls.

- Inertia constant and power capacity range Typical inertia constant $H=\{2-3\}$ s and power capacity range of $\{50-250\}$ MVA [13].

- Capital cost

SCs have a large cost range, which depends on the installation of new SC or converting exiting power plants into SC. However, an average cost for an SCs varies between $\{9-$ $35\} \mathrm{EUR} / \mathrm{kVAr}$ [86.

\section{Wind Turbines}

Wind Turbines are generally classified into Type 1, Type 2, Type 3 and Type 4 [18,87]. Early wind turbines of Type 1 and Type 2 were used with a constant speed asynchronous generator, which is directly connected to the power system and, thus, capable of providing synchronous inertia. Modern wind turbines (i.e. Type 3 and Type 4) are designed to operate at a wider range of rotor speeds. Their rotor speed varies with the wind speed or other system variables, based on the design employed. Additional speed and power controls allow variable-speed turbines to extract more energy from a wind regime than fixed-speed turbines. Nevertheless, for Type 3 and Type 4 turbines, power converters are required to interface the wind turbine with the grid and, thus, do not provide any inherent inertia response [88. However, several wind turbines manufactures offer synthetic inertia response control for the Type 3 and Type 4 wind turbines (e.g. ENERCON inertia emulation control and General Electric WindINERTIA) 89, 90. In this case, the attainable response from wind turbines is dependent on their operating condition prior to the imbalance. However, the energy extracted from the blades needs to be recovered to restore optimal operation and aerodynamic efficiency. The energy is generally recovered from the grid unless the wind speed increases favorably [91].

- Geographic limitation 
Location plays a significant role for the presence of the wind turbine itself. However, for existing wind turbines the geographic location should not present any limitation for providing these services.

- Additional system services

Wind turbines of Type 3 and Type 4 are capable of providing a wide range of system services due to their controllability. Nevertheless, they can only provide system services if sufficient wind is present.

- Type of the inertia response

Wind turbines of Type 1 and Type 2 provide inherent inertia response while Type 3 and Type 4 , in principal, can only provide emulated inertia.

- Inertia constant and power capacity range

Wind turbines of Type 1 and Type 2 with rated power more than $1 \mathrm{MW}$ have values of inertia constant in the range of $H=\{3-5\} \mathrm{s}$ [92. On the other hand, in Type 3 and Type 4 the mechanical inertia is decoupled from the grid. The machine power capacity spans between $\{1-10\}$ MW 78.

- Capital cost

Wind turbines capital cost varies among technologies. However, for onshore installation capital cost varies between $\{1100-1950\}$ EUR/kW while for offshore wind turbines, the capital cost varies between $\{2300-4300\}$ EUR/kW 93 .

\section{Demand Side Management}

In theory, demand and generation can participate in frequency control. In the current control schemes, adopted by the majority of TSOs, demand is used to restore severe power imbalance that cannot be alleviated by fast acting generators (i.e. load shedding). Nevertheless, demand capability to contribute to frequency control has been underestimated in the past due to the complexity involved in the realtime monitoring and control of aggregated loads 94. In contrast, with the advancements in measuring and monitoring techniques, demand side managements (DSMs) have started to gain more consideration and application from various TSOs in managing the power system efficiently and in accommodating a higher share of renewable energy generation 95. Simultaneously, different projects and studies are investigating DSM technology in providing additional system services as fast primary frequency control and SIC from aggregated loads. Various studies have conducted simulations and field tests to analyze the ability of electric vehicles to deliver frequency support and system services [34,66].
- Geographic limitation

Location plays a crucial role to allow the aggregation of a number of loads to provide adequate response power.

- Additional system services

DSM is able to provide multiple system services such as frequency and voltage control. However, the voltage control capability is generally within the distribution networks due to the resistive feature of low voltage (LV) networks. In fact, active power curtailment in LV networks becomes an effective solution to cope with voltage variations [96, 97.

- Type of the inertia response

DSM is able to provide regulating power in terms of emulated inertia. By controlling the active power consumption of a unit, it is possible to support the system frequency in terms of emulated inertia, namely by adding fast frequency control or synthetic inertia control [34].

- Inertia constant and power capacity range DSM does not provide inherent inertia response and, therefore, an inertia constant can not be provided. Similarly, a power capacity range can not be provided because it depends on the number of the aggregated electrical loads.

- Capital cost

DSMs have a large range of cost depending on the applied technology and infrastructure

\section{Flywheel}

Flywheels store kinetic energy in the rotation of a wheel. The moving mass is accelerated and decelerated by a motor/generator and, therefore, can charge or discharge the system [13. High speed flywheels are interfaced with the grid through power electronics, thus, are only capable of delivering synthetic inertia. Flywheels energy storage systems are characterized by their fast ramping ability and long-term durability. Due to their fast response time (i.e. in order of milliseconds), flywheels can provide ancillary services, including synthetic inertia and frequency response to power grids 98 .

- Geographic limitation

Flywheels do not have location restrictions and can easily be installed.

- Additional system services Flywheels are able to provide frequency support in terms of regulating power.

- Type of the inertia response

Due to the connection to the grid through power electronics, flywheels are only able to provide emulated inertia. 
- Inertia constant and power capacity range Flywheels are not characterized by an inertia constant due to the connection to the grid through power electronics. Their typical power capacity range between $\{0.1-20\}$ MW [78, 82.

- Capital cost

Flywheels have a capital cost that ranges between $\{210-300\} \mathrm{EUR} / \mathrm{kW} 82$.

\section{HVDC Interconnectors}

High-voltage DC (HVDC) transmission links provide a means of non-synchronously connecting two (or more) AC power systems whilst maintaining control of the power flow over the HVDC-link. An HVDClink is an economical way of transferring electrical power over long distances [99]. Due to the asynchronous interconnection between the interconnected power systems, no inherent inertia response is available because the DC connection fully decouples the two areas. Nevertheless, several studies have investigated the ability of HVDC to provide frequency control services, including inertia emulation and primary frequency control [100,101,102]. Frequency control can be achieved by including frequency control loop, either in the active power controller or the DC voltage controller 103 .

\section{- Geographic limitation}

The location of the HVDC interconectors plays a fundamental role in its applicability. Generally, the main challenge is related to the long distance and high costs.

- Additional system services

HVDC interconnectors are able to provide a large number of system services, depending on the employed converter technology. [104,105]. In [106, the following ancillary services are identified: reactive power/voltage control, frequency control and rotor angle stability related control. Moreover, the European Network of Transmission System Operators for Electricity (ENTSO-E) has started the development of a network code on high voltage direct current connections in which power oscillation damping capability and black start capability are included [105]. Assuming for example frequency support from Area 1 to Area 2 (i.e. the two terminals of the HVDC connections), the power has to pass through the DC grid. Thus, a DC transmission reserve must be guaranteed, so that in the case of activation, the frequency reserve can deliver the power at a defined point in the AC system. Similarly, by controlling the power flows in the interconnected power sys- tems, the HVDC has the ability to re-energize the AC system, which has been de-energized (i.e. black start capability).

- Type of the inertia response

Due to the decoupling between the two subsystems, only emulated inertia can be provided.

- Inertia constant and power capacity range HVDC interconnectors do not provide an inherent inertia response. HVDC power capacity depends from the employed technology. The current installed HVDC links are characterized by a power capacity in the range of $\{3-8000\}$ MW [78.

- Capital cost

HVDC capital cost depends on the applied technology and the distance over which the two areas are connected.

\section{Various Energy Storage Technologies}

Energy storage systems are units that store electrical energy and generally operate at direct current, thus, power electronic converters are needed to interface the units with the grid. Energy storage can provide multiple benefits to the power system in terms of ancillary services and RoCoF enhancement. Nevertheless, the unit's technology plays a fundamental role in deciding the suitability in providing such services. For example, Sodium-Sulfur batteries (NaS) are characterized by their fast response time and as claimed by certain manufactures, the response time is within $1 \mathrm{~ms}$ [107] allowing the provision of synthetic inertia services and/or fast frequency control services. On the other hand, hydrogen storage system and synthetic natural gas do have a relatively slow response time (i.e. in the range of seconds) which limits their capabilities for synthetic inertia services [108, 109 .

\section{- Geographic limitation}

Generally, batteries technologies do not have locational restrictions and are flexible to install. However, some minor exceptions might occur for flow batteries due to the additional space required for the auxiliary services and for the more complex technology.

- Additional system services Due to their controllability batteries are able to offer multiple system services.

- Type of the inertia response In principal, they can provide only emulated inertia.

- Inertia constant and power capacity range Batteries do not have any inherent inertia response. Batteries' power capacity depends on 
the applied technology, however, typical power capacity is generally up to several MW.

- Capital cost

Batteries' capital cost vary among the applied technologies. However, it can range between $\{250-2600\} \mathrm{EUR} / \mathrm{kW}$ [82].

\section{Conclusion}

The paper presented an overview of the various challenges which TSOs and distribution system operators (DSOs) are facing due to the increasing share of inertialess resources. It focuses generally on the frequency performance and in particular on the RoCoF. The effects of the system inertia and the primary frequency response on the RoCoF, frequency nadir and steady state value are presented graphically and analytically. The study presented also the various methods that can be employed to improve the frequency gradient, categorized into two groups, namely synchronous inertia and emulated inertia. The emulated inertia methods are divided into three groups, based on the applied control scheme, namely VSM, SIC and FFC.

The manuscript presented the key features and weaknesses of each control schemes detailing also the key parameters and challenges in applying those methods. However, as previously mentioned and shown by different publications, while both control schemes (i.e. FFC and SIC) are able to mitigate the RoCoF, better performance in terms of frequency nadir and steady state frequency is achieved when the FFC is applied [34,67].

Moreover, a qualitative investigation of the most prominent technologies that can be used to mitigate the RoCoF is presented. Each technology is assessed based on five criteria, namely, 1) Geographic limitation, 2) Additional system services (e.g. voltage control and black start), 3) Type of the provided inertia service, 4) Inertia constant $\mathrm{H}(\mathrm{s})$ and the typical power capacity (MW) and 5) Capital cost. The assessment showed that the adequate solution will depend mainly from the system requirement and the geographic restriction which can limit the applicability of certain technologies.

\section{References}

1. T. Ackermann. Wind Power in Power Systems. John Wiley, 2011.

2. M Marinelli, S Massucco, A Mansoldo, and M Norton. Analysis of Inertial Response and Primary PowerFrequency Control Provision by Doubly Fed Induction Generator Wind Turbines in a Small Power System. In 17th Power Systems Computation Conference, pages 1-7, 2011.
3. P. W. Christensen and G. T. Tarnowski. Inertia of wind power plants State of the art review. In The 10th International Workshop on Large-Scale of Wind Power, Aarhus, Denmark, 2011.

4. E. Muljadi, V. Gevorgian, M. Singh, and S. Santoso. Understanding inertial and frequency response of wind power plants. In 2012 IEEE Power Electronics and Machines in Wind Applications, pages 1-8, July 2012.

5. S. Sharma, S. H. Huang, and N. Sarma. System inertial frequency response estimation and impact of renewable resources in ERCOT interconnection. In 2011 IEEE Power and Energy Society General Meeting, pages 1-6, July 2011.

6. M. Pertl, T. Weckesser, M. Rezkalla, and M. Marinelli. Transient stability improvement: a review and comparison of conventional and renewable based techniques for preventive and emergency control. Springer Electrical Engineering, 2017.

7. P. Mancarella, S. Puschel, H. Wang, M. Brear, T. Jones, M. Jeppesen, R. Batterham, R. Evans, and I. Mareels. Power system security assessment of the future National Electricity Market. Technical Report June, Melbourne Energy Institute, Melbourne, 2017.

8. EIRGRID and SONI. RoCoF Alternative \& Complementary Solutions Project. Technical Report March, EIRGRID, 2016.

9. Luciano Martini, Luca Radaelli, Helfried Brunner, Chris Caerts, Andrei Morch, Seppo Hänninen, and Carlo Tornelli. ELECTRA IRP Approach to Voltage and Frequency Control for Future Power Systems with High DER Penetration. In 23rd International Conference on Electricity Distribution (CIRED), 2015.

10. M. Rezkalla, K. Heussen, M. Marinelli, J. Hu, and H. W. Bindner. Identification of requirements for distribution management systems in the smart grid context. In Power Engineering Conference (UPEC), 2015 50th International Universities, pages 1-6, Sept 2015.

11. The Commission for Energy Regulation. Rate of Change of Frequency ( RoCoF ) Modification to the Grid Code. Technical report, CER, 2014.

12. EirGrid and SONI. DS3 RoCoF Alternative Solutions Phase 1 Concluding Note. Technical report, EirGrid, 2015.

13. DNV GL Energy Advisory. RoCoF Alternative Solutions Technology Assessment. Technical report, DNVGL, 2015.

14. National Grid. Fast Reserve Service Description. Technical Report April, National Grid, 2013.

15. J. Brisebois and Noël Aubut. Wind Farm Inertia Emulation to Fulfill Hydro-Québec's Specific Need. In Power and Energy Society General Meeting IEEE, volume 7, pages 1-7, 2011.

16. Jeff Palermo. International review of frequency control adaptation. Technical report, DGA, 2016.

17. R Serway, R Beichner, and J. Jewett. Physics for Scientists and Engineers. Holt Rinehart \& Winston, Philadelphia, 5th edition, 2000.

18. M. Cheng and Y. Zhu. The state of the art of wind energy conversion systems and technologies: A review. Energy Conversion and Management, 88:332-347, 2014.

19. J. Licari, J. Ekanayake, and I. Moore. Inertia response from full-power converter-based permanent magnet wind generators. Journal of Modern Power Systems and Clean Energy, 1:26-33, 2013.

20. F. M. Gonzalez-longatt. Impact of emulated inertia from wind power on under-frequency protection schemes of future power systems. Journal of Modern Power Systems and Clean Energy, 4(2):211-218, 2016. 
Table 2: Overview of the various technologies

\begin{tabular}{|c|c|c|c|c|c|c|c|c|}
\hline \multirow[t]{2}{*}{ Technology } & \multirow{2}{*}{$\begin{array}{l}\text { Synch. } \\
\text { / EIC }\end{array}$} & \multirow{2}{*}{$\begin{array}{c}\text { Inertia } \\
(\mathbf{H})\end{array}$} & \multirow{2}{*}{$\begin{array}{c}\text { Power } \\
\text { capacity }\end{array}$} & \multirow{2}{*}{$\begin{array}{l}\text { Geography } \\
\text { limitations }\end{array}$} & \multicolumn{3}{|c|}{ Additional services } & \multirow{2}{*}{$\begin{array}{c}\text { Capital } \\
\text { cost }\end{array}$} \\
\hline & & & & & $\begin{array}{l}\text { Voltage } \\
\text { Support }\end{array}$ & $\begin{array}{l}\text { Energy } \\
\text { Supply }\end{array}$ & $\begin{array}{l}\text { Black } \\
\text { start }\end{array}$ & \\
\hline $\begin{array}{ll}\begin{array}{l}\text { Synchronous } \\
\text { densers }\end{array} & \text { Con- } \\
\text { den }\end{array}$ & Synch. & $\{2-3\} \mathrm{s}$ & $\begin{array}{c}\{50-250\} \\
\text { MVA }\end{array}$ & Low & YES & NO & NO & $\begin{array}{c}\{9-35\} \\
\text { EUR/kVAR }\end{array}$ \\
\hline $\begin{array}{ll}\text { Pumped } & \text { Storage } \\
\text { Hydro } & \end{array}$ & Synch. & $\{2-4\} \mathrm{s}$ & $\begin{array}{c}\{1-3000\} \\
\text { MW }\end{array}$ & High & YES & Limited & YES & $\begin{array}{l}\{800-1000\} \\
\text { EUR/kW }\end{array}$ \\
\hline $\begin{array}{l}\text { Compressed Air En- } \\
\text { ergy Storage }\end{array}$ & Synch. & $\{3-4\} \mathrm{s}$ & $\begin{array}{c}\{15-600\} \\
\text { MW }\end{array}$ & High & YES & Limited & YES & $\begin{array}{l}\{750-1000\} \\
\text { EUR/kW }\end{array}$ \\
\hline AC Interconnection & Synch. & $\begin{array}{l}\text { Depends } \\
\text { on the } \\
\text { intercon- } \\
\text { nected } \\
\text { systems }\end{array}$ & $\begin{array}{l}\text { Depends on } \\
\text { the line } \\
\text { rating }\end{array}$ & Medium & Limited & YES & Limited & - \\
\hline $\begin{array}{l}\text { Parking or Reduc- } \\
\text { tion of the mini- } \\
\text { mum MW genera- } \\
\text { tion }\end{array}$ & Synch. & $\{2-9\} \mathrm{s}$ & $\begin{array}{c}\text { Plant } \\
\text { dependent }\end{array}$ & Low & YES & YES & Limited & - \\
\hline $\begin{array}{l}\text { Wind } \quad \text { Turbines } \\
\text { (Type } 1 \& \text { 2) }\end{array}$ & $\begin{array}{l}\text { Synch. } \\
\text { \& EIC }\end{array}$ & $\{3-5\} \mathrm{s}$ & $0.5-2$ & Medium & Limited & YES & $\mathrm{NO}$ & $\begin{array}{c}\text { Onshore: } \\
\{1100- \\
1950\} \\
\text { EUR/kW }\end{array}$ \\
\hline $\begin{array}{l}\text { Wind } \quad \text { Turbines } \\
\text { (Type } 3 \& 4 \text { ) }\end{array}$ & $\begin{array}{l}\text { Synch. } \\
\text { \& EIC }\end{array}$ & - & $0.5-2$ & Medium & YES & YES & NO & $\begin{array}{l}\text { Offshore: } \\
\{2300- \\
4300\} \\
\text { EUR/kW }\end{array}$ \\
\hline $\begin{array}{l}\text { HVDC interconnec- } \\
\text { tors (VSC based) }\end{array}$ & EIC & - & $\begin{array}{c}\{100- \\
1000\} \mathrm{MW}\end{array}$ & Average & YES & YES & YES & \\
\hline $\begin{array}{l}\text { Electrochemical } \\
\text { and Chemical } \\
\text { Batteries }\end{array}$ & EIC & - & $\begin{array}{l}0.1-100 \\
\text { MW }\end{array}$ & Low & YES & Limited & YES & $\begin{array}{c}\{250-2600\} \\
\mathrm{EUR} / \mathrm{kW}\end{array}$ \\
\hline $\begin{array}{l}\text { Demand Side Man- } \\
\text { agement }\end{array}$ & EIC & - & $\begin{array}{l}\text { Depends on } \\
\text { the } \\
\text { aggregated } \\
\text { units } \\
\end{array}$ & Low & Limited & NO & NO & - \\
\hline Flywheels & EIC & - & $\begin{array}{c}\{0.1-20\} \\
\text { MW }\end{array}$ & Low & YES & $\mathrm{NO}$ & $\mathrm{NO}$ & $\begin{array}{c}\{210-300\} \\
\text { EUR/kW }\end{array}$ \\
\hline
\end{tabular}

21. U. Tamrakar, D. Galipeau, R. Tonkoski, and I. Tamrakar. Improving Transient Stability of Photovoltaic- Hydro Microgrids Using Virtual Synchronous Machines. In PowerTech, IEEE, Eindhoven, 2015.

22. U. Tamrakar, D. Shrestha, M. Maharjan, B. P Bhattarai, T. M. Hansen, and R. Tonkoski. applied sciences Virtual Inertia : Current Trends and Future Directions. Applied Sciences, pages 1-29, 2017.

23. H.P. Beck and R. Hesse. Virtual Synchronous Machine. In 9th International Conference on Electrical Power Quality and Utilisation, Barcelona, Spain, 2007.

24. S. D'Arco and J. Suul. Virtual Synchronous Machines Classification of Implementations and Analysis of Equivalence to Droop Controllers for Microgrids. In PowerTech IEEE, Grenoble, 2013.

25. J. Machowski, J. W. Bialek, and J. R. Bumby. Power System Dynamics and Stability. Wiley, Chichester, UK, 1997.

26. E. W. Kimbark. Power System Stability Volume III Synchronous Machines,. Wiley, New York, USA, 1956.

27. M. P.N. Van Wesenbeeck, S. W.H. De Haan, P. Varela, and K. Visscher. Grid tied converter with virtual kinetic storage. In IEEE Bucharest PowerTech: Innovative Ideas Toward the Electrical Grid of the Future, 2009.
28. J. Driesen and K. Visscher. Virtual Synchronous Generators. In Power and Energy Society General Meeting, pages 1-3, Pittsburgh, PA, USA, 2008.

29. V. Karapanos, S. Haan, and K. Zwetsloot. Real Time Simulation of a Power System with VSG Hardware in the Loop. In IECON - 37th Annual Conference on IEEE Industrial Electronics Society, pages 1-7, Melbourne, VIC, Australia, 2011

30. V. Thong, A. Woyte, M. Albu, M. Hest, J. Bozelie, J. Diaz, T. Loix, D. Stanculescu, and K. Visscher. Virtual Synchronous Generator : Laboratory Scale Results and Field Demonstration. In PowerTech IEEE, pages 1-6, Bucharest, 2009.

31. Y. Chen, R. Hesse, D. Turschner, and H.P. Beck. Comparison of methods for implementing virtual synchronous machine on inverters. In International Conference on Renewable Energies and Power Quality, pages 1-6, Santiago de Compostela, 2012.

32. C. Pelczar. Mobile Virtual Synchronous Machine for Vehicle-to-Grid Applications. PhD thesis, Clausthal University of Technology, 2012.

33. M. Marinelli, S. Martinenas, K. Knezovi, and P. B. Andersen. Validating a centralized approach to primary 
frequency control with series-produced electric vehicles. Journal of Energy Storage, 7:63 - 73, 2016.

34. M. Rezkalla, A. Zecchino, S. Martinenas, A.M. Prostejovsky, and M. Marinelli. Comparison between synthetic inertia and fast frequency containment control based on single phase EVs in a microgrid. Applied Energy, 2017.

35. Spark Xue, Bogdan Kasztenny, Ilia Voloh, and Dapo Oyenuga. Power System Frequency Measurement for Frequency Relaying. In Western Protective Relay Conference, At Spokane, WA, 2007.

36. M. M. BegoviC, P. M. DjuriC, S. Dunlap, and A. G. Phadke. Frequency Tracking ih Power Networks in the Presence of Harmonics. IEEE Transactions on Power Delivery, 8(2):480-486, 1993.

37. L. Asnin, V. Backmutsky, M. Gankin, J Blashka, and M Sedlachek. DSP methods for dynamic estimation of frequency and magnitude parameters in power system transients. In IEEE Power Tech Conference, pages 1-6, Porto, 2001.

38. C.T. Nguyen and K. Srinivasan. A New Technique for Rapid Tracking of Frequency Deviations Based on Level Crossings. IEEE Transactions on Power Apparatus and Systems, 8(8):2230-2236, 1984.

39. D. Hart, D. Novosel, Y. Hu, B. Smith, and M. Egolf. A new frequency tracking and phasor estimation algorithm for generator protection. IEEE Transactions on Power Delivery, 12(3):1064-1073, 1997.

40. B. Kasztenny and E. Rosolowski. Two New Measuring Algorithms for Generator and Transformer Relaying. IEEE Transactions on Power Delivery, 13(4):1053-1059, 1998.

41. M. Wang and Y. Sun. A Practical, Precise Method for Frequency Tracking and Phasor Estimation. IEEE Transactions on power delivery, 19(4):1547-1552, 2004.

42. V. Eckhardt, P. Hippe, and G. Hosemann. Dynamic measuring of frequency and frequency oscillations in multiphase power systems. IEEE Transactions on Power Delivery, 1989.

43. M Karimi-Ghartemani and M.R Iravani. Wide-range, fast and robust estimation of power system frequency. Electric Power Systems Research, 2003.

44. H. Karimi, M. Karimi-Ghartemani, and M.R. Iravani. Estimation of Frequency and its Rate of Change for Applications in Power Systems. IEEE Transactions on Power Delivery, 2004.

45. P.J. Moore, R.D. Carranza, and A.T. Johns. A new numeric technique for high-speed evaluation of power system frequency. IEE Proceedings - Generation, Transmission and Distribution, 1994.

46. T S Sidhu. Accurate measurement of power system frequency using a digital signal processing technique. IEEE Transactions on Instrumentation and Measurement, 1999.

47. P. K. Dash, G. Panda, A. K. Pradhan, A. Routray, and B. Duttagupta. An extended complex Kalman filter for frequency measurement of distorted signals. In 2000 IEEE Power Engineering Society, Conference Proceedings, 2000.

48. H.C. Lin. Fast tracking of time-varying power system frequency and harmonics using iterative-loop approaching algorithm. IEEE Transactions on Industrial Electronics, 2007.

49. Z. Salcic, Z. Li, U.D. Annakkage, and N. Pahalawaththa. A comparison of frequency measurement methods for underfrequency load shedding. Electric Power Systems Research, 1998.
50. J P Patra and P. K. Dash. Fast frequency and harmonic estimation in power systems using a new optimized adaptive filter. Electrical Engineering, pages 171-184, 2012.

51. J. Wu, J. Long, and J. Wang. High-accuracy, wide-range frequency estimation methods for power system signals under nonsinusoidal conditions. IEEE Transactions on Power Delivery, 2005.

52. M. B. Duric, V V Terzija, and I A Skokljev. Power system frequency estimation utilizing the Newton-Raphson method. Electrical Engineering, 77:221-226, 1994.

53. P K Dash, S K Panda, B Mishra, and D P Swain. Fast estimation of voltage and current phasors in power networks using an adaptive neural network. IEEE Transactions on Power Systems, 1997.

54. Khaled M. El-Naggar and Hosam K.M. Youssef. Genetic based algorithm for frequency-relaying applications. Electric Power Systems Research, 2000.

55. P. Kostyla, T. Lobos, and Z. Waclawek. Neural networks for real-time estimation of signal parameters. Proceedings of IEEE International Symposium on Industrial Electronics, 1996.

56. P. Kundur, J. Paserba, V. Ajjarapu, G. Andersson, A. Bose, C. Canizares, N. Hatziargyriou, D. Hill, A. Stankovic, C. Taylor, T. Van Cutsem, and V. Vittal. Definition and Classification of Power System Stability. IEEE Transactions on Power Systems, 21(3):1387-1401, 2004.

57. K. Temtem, S.and Creighton. Summary of Studies on Rate of Change of Frequency events on the All-Island System. Technical Report August 2012, Entso-E, 2012.

58. EirGrid. RoCoF Modification Proposal - TSOs Recommendations. Technical Report September, EirGrid, 2012.

59. W. Xu, K. Mauch, and S. Martel. An Assessment of Distributed Generation Islanding Detection Methods and Issues for Canada. Technical report, CETC, Canada, 2004.

60. X Ding, P A Crossley, and D J Morrow. Islanding Detection for Distributed Generation. Journal of Electrical Engineering $\&$ TechnologyJournal of Electrical Engineering 85 Technology, 2007.

61. A. Beddoes, P. Thomas, and M. Gosden. Loss of mains protection relay performances when subjected to network disturbances / events. In 18th International Conference on Electricity Distribution CIRED, pages 1-5, 2005.

62. CHUI FEN TEN. Loss of Mains Detection and Amelioration on Electrical Distribution Networks. PhD thesis, University of Manchester, 2010.

63. A.A.M. Hassan and Tarek A. Kandeel. Effectiveness of frequency relays on networks with multiple distributed generation. Journal of Electrical Systems and Information Technology, 2015.

64. W. Uijlings. An independent analysis on the ability of Generators to ride through Rate of Change of Frequency values up to $2 \mathrm{~Hz} / \mathrm{s}$. Technical report, Uijlings, 2013.

65. Tom Mccartan. Rate of Change of Frequency ( RoCoF ) project Six Monthly Report for November 2016. Technical Report November, ForskEl Project, 2016.

66. K. Knezović, M. Marinelli, A. Zecchino, P. B. Andersen, and C. Traeholt. Supporting involvement of electric vehicles in distribution grids: Lowering the barriers for a proactive integration. Energy, 134:458-468, 2017.

67. M. Rezkalla, M. Marinelli, M. Pertl, and K. Heussen. Trade-off Analysis of Virtual Inertia and Fast Primary Frequency Control during Frequency Transients in a Converter Dominated Network. In Innovative Smart 
Grid Technologies - Asia (ISGT-Asia), IEEE, pages 1-6, Melbourne, VIC, Australia, 2016.

68. L. Pereira, J. Undrill, D. Kosterev, D. Davies, and S. Patterson. A New Thermal Governor Modeling Approach in the WECC. IEEE Transactions on Power Systems, 18(2), 2003.

69. N W Miller, M Shao, S Pajic, and R D Aquila. Eastern Frequency Response Study. Technical Report May, NREL, 2013.

70. Energinet.dk. Ancillary services to be delivered in Denmark Tender conditions. Technical report, Energinet, Fredericia, 2012.

71. ENTSO-E. Frequency Stability Evaluation Criteria for the Synchronous Zone of Continental Europe. Technical report, ENTSOE, 2016.

72. C. S. Schifreen and W. C. Marble. Charging current limitations in operation or high-voltage cable lines [includes discussion]. Transactions of the American Institute of Electrical Engineers. Part III: Power Apparatus and Systems, 75(3), Jan 1956.

73. L. Chen, T. Zheng, S. Mei, X. Xue, B. Liu, and Q. Lu. Review and prospect of compressed air energy storage system. Journal of Modern Power Systems and Clean Energy, 4(4):529-541, 2016.

74. Brian Elmegaard and Wiebke Brix Markussen. Efficiency of Compressed Air Energy Storage. In The 24th International Conference on Efficiency, Cost, Optimization, Simulation and Environmental Impact of Energy Systems, 2011.

75. Ebrahim Vaahedi. Practical Power System Operation. John Wiley \& Sons, 1st edition, 2014.

76. A. E. Tønnesen, A. H. Pedersen, B. Elmegaard, J. Rasmussen, J. H. Vium, L. Reinholdt, and A. S. Pedersen. Electricity Storage Technologies for Short Term Power System Services at Transmission Level. Technical Report October, ForskEl Project, 2010.

77. J. Macak. Evaluation of Gas Turbine Startup and Shutdown Emissions for New Source Permitting. Technical report, Mostardi Platt Environmental, Florida, 2014.

78. S. Rehman, L. M. Al-Hadhrami, and M. M. Alam. Pumped hydro energy storage system: A technological review. Renewable and Sustainable Energy Reviews, 2015.

79. M. Mohanpurkar, A. Ouroua, R. Hovsapian, Y. Luo, M. Singh, E. Muljadi, V. Gevorgian, and P. Donalek. Real-time co-simulation of adjustable-speed pumped storage hydro for transient stability analysis. Electric Power Systems Research, 154:276-286, 2018.

80. E; Ela, B; Kirby, A; Botterud, C; Milostan, I; Krad, and V; Koritarov. Role of Pumped Storage Hydro Resources in Electricity Markets and System Operation. In $\mathrm{Hy}$ droVision International Denver, Colorado, July 23-26, 2013, 2013.

81. NHA Pumped storage council. Challenges and Opportunities For New Pumped Storage Development. Technical report, NHA, 2012.

82. X. Luo, J. Wang, M. Dooner, and J. Clarke. Overview of current development in electrical energy storage technologies and the application potential in power system operation. Appl. Energy, 2015.

83. S. Nakamura, T Yamada, T Nomura, M. Iwamoto, Y. Shindo, S. Nose, H. Fujino, and A. Ishihara. 30 MVA superconducting synchronous condenser: Design and it's performance test results. IEEE Transactions on Magnetics, 21(2):783-790, 1985.
84. J.A. Oliver, B J Ware, and R.C. Carruth. 345 MVA Fully Water-Cooled Synchronous Condenser for Dumont Station Part I. Application Considerations. IEEE Transactions on Power Apparatus and Systems, PAS-90(6):27582764, 1971.

85. H. T. Nguyen, G. Yang, A. H. Nielsen, and P. H. Jensen. Frequency stability improvement of low inertia systems using synchronous condensers. In 2016 IEEE International Conference on Smart Grid Communications, SmartGridComm 2016, 2016.

86. J Kueck, B Kirby, T Rizy, F Li, and N Fall. Reactive Power from Distributed Energy. The Electricity Journal, 2006.

87. E Muljadi and A. Ellis. Validation of Wind Power Plant Models. In IEEE Power and Energy Society General Meeting, pages 1-7, 2008.

88. M. Singh and S. Santoso. Dynamic Models for Wind Turbines and Wind Power Plants Dynamic Models for Wind Turbines and Wind Power Plants. Technical Report May, NREL, 2011.

89. Y C Zhang, V Gevorgian, and E Ela. Role of Wind Power in Primary Frequency Response of an Interconnection Preprint. In International Workshop on Large-Scale Integration of Wind Power Into Power Systems as Well as on Transmission Networks for Offshore Wind Power Plants, 2013.

90. E. Muljadi, V. Gevorgian, M. Singh, and S. Santoso. Understanding inertial and frequency response of wind power plants. 2012 IEEE Power Electronics and Machines in Wind Applications, pages 1-8, 2012.

91. Lisa Ruttledge and Damian Flynn. Emulated Inertial Response from Wind Turbines: The Case for Bespoke Power System Optimisation. In International Workshop on Large-Scale Integration of Wind Power into Power Systems as well as on Transmission Networks for Offshore Wind Power Plants, 2012.

92. J. Morren, J. Pierik, and S. W H De Haana. Inertial response of variable speed wind turbines. Electric Power Systems Research, 2006.

93. IRENA. Wind power - Technology Brief. Technical report, IRENA, 2016.

94. M H Syed, P Crolla, G M Burt, and J. K. Kok. Ancillary Service Provision by Demand Side Management : A Real-Time Power Hardware-in-the- loop Co-simulation Demonstration. In Smart Electric Distribution Systems and Technologies, pages 1-7, 2015.

95. EirGrid. DS3 Demand Side Management Workstream Plan. Technical Report May, EIRGRID, 2016.

96. A. N.M.M. Haque, P. H. Nguyen, T. H. Vo, and F. W. Bliek. Agent-based unified approach for thermal and voltage constraint management in LV distribution network. Electric Power Systems Research, 143:462-473, 2017.

97. Antonio Zecchino and Mattia Marinelli. Analytical assessment of voltage support via reactive power from new electric vehicles supply equipment in radial distribution grids with voltage-dependent loads. International Journal of Electrical Power and Energy Systems, 97(October 2017):17-27, 2018.

98. N Lu, M R Weimar, Y V Makarov, F. J. Rudolph, S. N. Murthy, and J. Arseneaux. An Evaluation of the Flywheel Potential for Providing Regulation Service in California. In Power and Energy Society General Meeting, pages 1-6, 2010.

99. G. Mazzanti and M. Marzinotto. Fundamentals of HVDC Cable Transmission. In Extruded Cables for High-Voltage 
Direct-Current Transmission:Advances in Research and Development, chapter 2. Wiley-IEEE Press, 2013.

100. G J Georgantzis, N A Vovos, and G B Giannakopoulos. A suboptimal static controller for HVDC links supplying isolated AC networks. Electrical Engineering, 75(6):451458, 1992.

101. B Silva, C L Moreira, L Seca, Y Phulpin, and J. A. Peças Lopes. Provision of Inertial and Primary Frequency Control Services Using Offshore Multiterminal HVDC Networks. IEEE TRANSACTIONS ON SUSTAINABLE ENERGY, 3(4):800-808, 2012.

102. M. Andreasson, R.r Wiget, D. V. Dimarogonas, K. H. Johansson, and G. Andersson. Distributed Primary Frequency Control through Multi-Terminal HVDC Transmission Systems. In American Control Conference $(A C C)$, pages 1-6, Chicago, IL, USA, 2015.

103. C. Du, E. Agneholm, and G. Olsson. Comparison of different frequency controllers for a VSC-HVDC supplied system. IEEE Transactions on Power Delivery, 2008.

104. Kjell Eriksson and John Graham. HVDC Light a transmission vehicle with potential for ancillary services. In VII SEPOPE-Conference, pages 1-6, 2000.

105. Entso-e. ENTSO-E Draft Network Code on High Voltage Direct Current Connections and DC- connected Power Park Modules. Technical Report April, Entso, 2014.

106. Yannick Phulpin and Damien Ernst. Ancillary services and operation of multi-terminal HVDC systems. In International Workshop on Transmission Networks for Offshore Wind Power Plants as well as on Transmission Networks for Offshore Wind Power Farms, number October, pages 1-6, 2011.

107. NGK INSULATORS. Structure of NAS Energy Storage System Principle of NAS Battery. Technical report, NGK INSULATORS, 2008.

108. International Electrotechnical Commission. Electrical Energy Storage. Technical report, IEC, 2015.

109. US Department of Energy. Grid Energy Storage. Technical Report December, U.S. Department of Energy, 2013. 